various stages of this study, and Miss Nancy Rogers and Mrs. Anne Watkins, who performed much of the technical analyses. Misses L. Dalby, W. Thoren, and L. Shannon assisted with the bedside haemodynamic measurements.

\section{REFERENCES}

Askrog, V. (1966). F. app. Physiol., 21, 1299.

Fowler, W. S., Cornish, E. R., and Kety, S. S. (1952). F. clin. Invest., 31, 40
MacKenzie, G. J., Taylor, S. H., Flenley, D. C., McDonald, A. H., Staunton, H. P., and Donald, K. W. (1964). Lancet, 2, 825. McNicol, M. W., Kirby, B. J., Bhoola, K. D., Everest, M. E., Price, H. V., and Freedman, S. F. (1965). Brit. med. F., 2, 1270.

Riley, R. L and Cournand, A. (1949). F. appl. Physiol., 1, 825.

Rey, R. L., and Cournand, A. (1949).

Robinson, J. S., and Sloman, G. (1965). M5.

Sloman, J. G., Stock, E., and Johnson, A. (1966). Aust. Ann. Med., 15, 373.

Valentine, P. A., Fluck, D. C., Mounsey, J. P. D., Reid, D., Shillingford, J. P., and Steiner, R. E. (1966). Lancet, 2, 837.

West, J. B., and Jones, N. L. (1965). F. appl. Physiol., 20, 825.

\title{
Aversion Therapy in Management of 43 Homosexuals
}

\author{
M. J. MACCULLOCH, ${ }^{*} \dagger$ M.B., CH.B., D.P.M. ; M. P. FELDMAN, ${ }^{*} \ddagger$ PH.D.
}

Brit. med. f., 1967, 2, 594-597

A wide variety of techniques have been used in the treatment of homosexuality. They include psychotherapy, psychoanalysis, hormones, and several types of aversion therapy. There are relatively few published reports involving more than a small number of patients. To date, only one series of patients treated by aversion therapy has appeared (Freund, 1960). This involved the use of apomorphine as the aversive stimulus. A satisfactory response to treatment was obtained in $25 \%$ of all cases, but this was only after patients referred by the courts had been excluded. The same percentage of success was obtained in a series of 100 patients treated by psychoanalytic techniques (Bieber et al., 1962). Follow-up data for this series have not been reported. The two British series which have been published obtained treatment results which were even less satisfactory than those of Freund and of Bieber et al.

Curran and Parr (1957) were able to follow up 52 out of their original 100 patients, most of whom received psychotherapy, and in only nine was there a change of preference towards heterosexuality. Woodward (1958), reporting a series of patients treated at the Portman Clinic and referred by the courts, found that out of the 48 who completed treatment without interruption only seven had no homosexual impulse and an increased heterosexual interest and activity. Very little follow-up data are available for Woodward's series. It seems, therefore, that in the published series approximately one-quarter at best of treated homosexual patients make a satisfactory response to treatment in that they display a noticeable change in the direction of their sexual preference and practice towards heterosexuality. Such follow-up data as are available suggest prevention of relapse to be one of the major problems in the treatment of homosexuality.

\section{Method of Study}

The present paper is a report on a series of 43 homosexual patients treated by us and our colleagues over a period of three and a quarter years, by means of the technique of anticipatory avoidance learning using an electrical aversive stimulus. The minimum period of follow-up is 12 months. A preliminary report on the technique has appeared elsewhere (Feldman and MacCulloch, 1964) and a detailed description is given in an account (Feldman and MacCulloch, 1965) of the response to treatment of the first 19 patients. A survey of the results of treatment of homosexuality by aversion therapy, together with a critical account of the aversive techniques used to date, has also been presented (Feldman, 1966). A brief account of the technique used by us follows.

* Department of Psychiatry, Crumpsall Hospital, Manchester. + Now Consultant Psychiatrist, Cheshire County Council. ‡Now Lecturer, Department of Psychology, Birmingham University.

\section{Treatment Technique}

The homosexual patient views a slide of a male which is back-projected on to a screen. He is instructed to leave this picture on for as long as he finds it attractive. After the slide has been on the screen for eight seconds the patient receives an electric shock if he has not by then removed it by means of a hand switch (with which he is provided). If he does switch off within the eight-second period he avoids the shock. The circuit is so wired that the patient's attempts to switch off can be delayed by the therapist. A schedule of reinforcement is used so that one-third of all the patient's attempts to switch off are delayed but do eventually remove the male slide within the eight-second period; one-third are non-reinforced-that is, the patient is shocked despite his attempts to switch offand one-third result in the picture being removed immediately. This mixture of trials has been shown to assist considerably in delaying extinction (relapse). A photograph of a female is introduced and remains on the screen for 10 seconds immediately the male slide leaves the screen, but in order to preserve the principle of unpredictability the female slide is not introduced on every possible occasion. Finally, the patient can press his switch to request the return of the female slide should he wish to do so. Once again his request is not met on every occasion but only randomly.

The whole treatment situation and the various variables referred to above are designed to make the fullest possible use of the extensive knowledge available to us of the psychology of learning (Kimble, 1961). The slides are first set up by the patient in a hierarchy of attractiveness, and we begin with a male slide which is only mildly attractive, working up to one which is very attractive. The opposite is carried out with the female slides, beginning with one which is relatively attractive to the patient and gradually moving along the hierarchy. The aversive stimulus (unconditional stimulus) is provided by a 12 -volt make/break induction coil and is controlled by a rheostat. About 24 stimulus presentations are used per session, and each session lasts for about 20 to 25 minutes. On average each patient receives 18 to 20 sessions of treatment. Treatment is continued until either a change of interest occurs or it becomes clear that no change is likely. A number of patients (see below) have discontinued treatment of their own accord.

Recently we have been carrying out a controlled trial of the technique described above, in which it is compared with classical conditioning and psychotherapy. The results of this will be reported later. Both the apparatus and the treatment technique employed have been made somewhat more complicated and advanced so as to increase the degree of control over the situation exercised by the therapist. 


\section{Results}

Forty-three patients are reported here. We offered treatment $\omega$ all those who presented; no selection criteria other than the inevitable self-selection (two potential patients declined the offer) have been used. Unless all patients are accepted for treatment no true assessment of criteria prognostic of success (see below) can be made. Thirty-six patients had the full course of treatment, and seven failed to complete it. Six of the seven terminated treatment after one or two sessions, and one terminated it after six sessions. The data which follow refer to the entire sample of 43 , and are presented in sufficient detail to enable comparison with other published series.

The ages of the patients when they first presented for treatment are shown in Table I ; it will be seen that there is no great preponderance of very young patients, nine of the sample being over the age of 40 . The group who failed to complete treatment were fairly evenly distributed throughout the age ranges. Seven of the series, including one of those who failed to complete treatment, were married. Two of the series were females, and were partners in a lesbian " affair"; both were aged 18, and both completed treatment. All other patients were male homosexuals.

\begin{tabular}{|c|c|c|c|c|c|c|c|}
\hline $\begin{array}{l}\text { Age range } \\
\text { No. } \quad . .\end{array}$ & .. & $\frac{15-20}{5}$ & $\stackrel{21-25}{8}$ & $\begin{array}{c}26-30 \\
10\end{array}$ & $\begin{array}{c}31-35 \\
8\end{array}$ & $\frac{36-40}{3}$ & $\begin{array}{r}40+ \\
9\end{array}$ \\
\hline
\end{tabular}

Table II presents the reason why patients appeared for treatment. Eighteen (42\%) did so either on an order of the court, as the sequel to a court appearance, or previous to a court appearance. To some extent this is due to the fact that the Director of the Department of Psychiatry at Crumpsall is a forensic psychiatrist. Only four patients presented with symptoms other than their homosexuality, and all of them requested treatment when they learned that it was available. It is of some interest that of the seven who failed to complete treatment five presented either on an order of the court or were in some way connected with a court appearance.

TABLE II.-Reasons for Appearing for Treatment

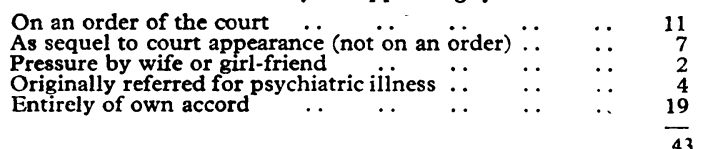

We are not here presenting data on social class and other social factors, but the school performance was poor in 5 , average in 13 , good in 4 , and 21 passed the $11+$ examination equivalent; a rather higher proportion in the series had a secondary grammar school education than is probably the case in the population at large. Motivation for treatment was assessed at the first interview ; this was low in 5, equivocal in 13, and strong in 25. All but one of those who failed to complete treatment were in the low or equivocal group. The age of the patient's preferred sexual partner was under 16 in only seven cases, therefore five-sixths of the sample preferred adults to young boys. There was little or no overlap here, the direction of sexual object choice being either youngsters or adults. The numbers charged and found guilty of homosexual offences at some time previous to presentation were: one offence in 17 cases, two offences in four cases, and three or more offences in one case. Thus half the series had been charged and found guilty of at least one offence.

Considerable care was taken to make as full as possible an examination of the psychiatric status and personality features of the patients. The personality classification used is that of Schneider (1958). In Table III it can be seen that 25 of the sample had a personality disorder on presentation. In most cases this was of the kind which causes the patient to suffer rather than causing other people to suffer. One patient was displaying a post-schizophrenic defect state. Fifteen patients were displaying an acute psychogenic reaction to the circumstances, either of their homosexuality or of a court appearance associated with it, when they first presented. Thirteen displayed an abnormal psychogenic development throughout the course of their lives ; that is, the development of unusual self-perceptions based either on their homosexuality or on other people's real or imagined reactions to it.

\begin{tabular}{|c|c|c|c|c|c|c|}
\hline TABLE & III. $-P$ & & Status & on & Pre & tion \\
\hline Current & $\left\{\begin{array}{l}\text { Schizo } \\
\text { Person }\end{array}\right.$ & & $\begin{array}{l}\text { fect state } \\
\text { ler }\end{array}$ & & $\because$ & $\because$ \\
\hline disorder & Nil .. & .. & . & . & . & .. \\
\hline Acute & $\int$ Yes & .. & $\cdots$ & . & .. & $\cdots$ \\
\hline reaction & No & . & .. & . & . & .. \\
\hline $\begin{array}{l}\text { Abnormal } \\
\text { psychogenic }\end{array}$ & $\int$ Yes & . & . &. & & \\
\hline devel & (No & . & . & .. & . & $\ldots$ \\
\hline
\end{tabular}

\section{Sexual Practices}

We now present data concerning the nature and degree of our patients' sexual practices. Twenty-four of the series had been practising homosexuality overtly for more than 10 years, and only two had never practised but instead had exclusively utilized strong homosexual fantasy (Table IV). Several other patients were not actively practising homosexuality at the time of presentation but were using predominantly homosexual fantasy (Table V). Twenty-five of the patients were displaying no heterosexual practice or fantasy of any kind (Table V). Of the nine patients who did use heterosexual fantasy, only two did so to a marked degree. There were nine patients in all who were heterosexually active on presentation. Seven of these were having sexual intercourse, in five cases with their wives. All five of these patients had to utilize homosexual fantasy on at least some occasions in order to maintain an erection. In these instances, therefore, the behaviour was that of masturbation per vaginam (Curran and Parr, 1957). Frequent overt homosexual behaviour was displayed by all five of these heterosexually active married patients. Both lesbian patients were practising heterosexual intercourse with a variety of partners. Neither patient found this pleasurable, and both felt a considerable degree of contempt for their male partners.

TABle IV.-Duration of Homosexual Practice

\begin{tabular}{ll|l|l|c|c|c|c|c|c}
\hline Years of practice &.. & 0 & $1-2$ & $3-4$ & $5-6$ & $7-8$ & $9-10$ & $>10$ \\
No... &. &.. & 2 & 5 & 1 & 4 & 1 & 6 & 24 \\
\hline
\end{tabular}

TABLE V.-Major Homosexual and Heterosexual Practice on Presentation

\begin{tabular}{|c|c|c|c|c|}
\hline Homosexual Practice & \multicolumn{4}{|c|}{ Heterosexual Practice } \\
\hline $\begin{array}{ll}\text { Strong fantasy only } & 8 \\
\text { Mutual masturbation } & 9\end{array}$ & $\begin{array}{l}\text { Weak fantasy ... } \\
\text { Strong } " .\end{array}$ & $\begin{array}{l}7 \\
2\end{array}$ & Petting . . . . & 1 \\
\hline $\begin{array}{lll}\text { Buggery } & \cdots & 26\end{array}$ & $\begin{array}{l}\text { Dating } \\
\text { Kissing }\end{array}$ & $\begin{array}{l}0 \\
1\end{array}$ & $\begin{array}{llll} & \mathrm{Nil} & . & \end{array}$ & 25 \\
\hline
\end{tabular}

The data presented above on heterosexual and homosexual behaviour can be combined to yield a Kinsey rating (Kinsey, Pomeroy, and Martin, 1948). Nineteen of the sample had a Kinsey rating of 6 and 12 a Kinsey rating of 5 , giving a total of $31(72 \%)$ with Kinsey ratings of 5 or 6 (Table VI). One relevant comparison is with Curran and Parr's series, in which $42 \%$ had a Kinsey rating of 5 or 6 . Only 12 of our series were rated as Kinsey 3 and 4, in whom there is a reasonably strong heterosexual component.

TABLE VI.-Pretreatment Kinsey Rating

\begin{tabular}{ll|l|l|l|l|l|l|l|l}
\hline Kinsey rating & $\ldots$ & 0 & 1 & 2 & 3 & 4 & 5 & 6 \\
No... & $\cdots$ & $\cdots$ & 0 & 0 & 0 & 5 & 7 & 12 & 19 \\
\hline
\end{tabular}


We next present data to demonstrate the degree to which at least some of our series had adapted to a homosexual way of life. Fifteen patients had had one homosexual "affair," seven had had two affairs, eight had had three or more affairs. An affair is the situation in which there is a sexual and emotional relationship between two males lasting several weeks or more. Only 13 of the series had never had such an affair. Finally, 21 patients frequented homosexual coteries and 22 did not.

\section{Results of Treatment}

It can be stated, before presenting the detailed data, that of the 36 patients who completed treatment 25 improved to a sufficient degree for their treatment to be described as successful, 11 were unimproved, and seven failed to complete the treatment. The criteria for this are presented below. All the 25 patients who are regarded as improved have been followed up for at least one year, and many have been followed up for two years or more. Of the 11 patients who failed to improve, the majority have been followed up for at least one year. In the case of two patients who initially improved no follow-up appointments were kept. It was therefore concluded that they relapsed and they are included in the "failed to improve" group. We have lost contact with two of the other patients who failed to improve, and it is concluded that no spontaneous improvement occurred. It is assumed that the seven patients who failed to complete treatment are displaying the same sexual practices as before treatment; that is, that they have failed to improve. This should be borne in mind when comparing the data on heterosexual and homosexual practices after treatment.

Table VII presents data on heterosexual practice at the time of the latest follow-up-that is, at least one year after completion of treatment. It can be seen that 13 patients were then having active heterosexual intercourse, and in all cases this was unaccompanied by homosexual fantasy or practice. Seven other patients were actively practising heterosexually. Two were mixing socially with females and were beginning to approach active heterosexual practice. Finally, three patients out of the five shown were improved in the homosexual area and were using strong heterosexual fantasy. Two patients in the failed group continued to use strong heterosexual fantasy, as they did previous to treatment, together with overt homosexual activity. There were 14 patients as compared with 25 before treatment who had no heterosexual fantasy or practice. Table VII also presents data on homosexual practice after treatment at the latest follow-up. It can be seen that 20 patients were neither using homosexual fantasy nor displaying overt homosexual practice. Nine patients were using homosexual fantasy ; five of them, however, to only a weak degree. The remainder were still displaying overt homosexual activity.

\begin{tabular}{l|lr|lll|ll} 
TABLB VII.-Major Heterosexual and Homosexual Practice After \\
Treatment
\end{tabular}

The above data on heterosexual and homosexual behaviour after treatment form the basis for Table VIII, which is concerned with the Kinsey ratings of the series at the latest followup. It can be seen that 14 patients were Kinsey 0 , nine Kinsey 1 , and two Kinsey 2 (making up the 25 improved patients), the remainder all being Kinsey 3 to 6 . The two patients who were rated as Kinsey 2 are included in the improved group because before treatment they were Kinsey 6 , and had therefore shown a very considerable improvement. The two lesbian patients had made a very good improvement and neither displayed any homosexual fantasy, interest, or practice. One of them was still practising heterosexual intercourse ; and, compared with her practice before treatment, she did so with great pleasure and had a high regard for her partner, who was a relatively permanent one. The other lesbian patient no longer practised heterosexual intercourse but had a good heterosexual relationship with her partner, again a fairly stable one. That 20 patients were displaying no homosexual practice or fantasy but only 14 could be rated as Kinsey 0 is accounted for by the fact that the other six were still displaying an occasional and very slight degree of homosexual interest in directly observed males without, however, any subsequent fantasy. Because we are trying to make our criteria as strict as possible, it has been decided to rate these patients as Kinsey 1 .

TABLE VIII.-Post-treatment Kinsey Ratings

\begin{tabular}{|c|c|c|c|c|c|c|c|c|}
\hline \multirow[b]{2}{*}{$\begin{array}{l}\text { Kinsey rating } \\
\text { No. } \quad . \quad .\end{array}$} & \multirow[b]{2}{*}{$\because$} & \multicolumn{3}{|c|}{ Improved } & \multicolumn{4}{|c|}{$\begin{array}{l}\text { Unimproved and Failed to } \\
\text { Complete }\end{array}$} \\
\hline & & $\begin{array}{r}0 \\
14\end{array}$ & $\begin{array}{l}1 \\
9\end{array}$ & $\begin{array}{l}2 \\
2\end{array}$ & $\begin{array}{l}3 \\
2\end{array}$ & $\begin{array}{l}4 \\
3\end{array}$ & $\begin{array}{l}\mathbf{5} \\
\mathbf{3}\end{array}$ & $\begin{array}{r}6 \\
10\end{array}$ \\
\hline
\end{tabular}

\section{Discussion}

The results of treatment of 43 patients treated by anticipatory avoidance learning are presented. We are preparing a detailed analysis of factors which are prognostic of success and failure in response to treatment with this technique, and some preliminary findings are briefly mentioned below.

\section{Degree of Homosexuality}

Table IX compares the pretreatment Kinsey ratings of the patients who improved with the ratings of those who failed to improve or failed to complete treatment. Two points may be made in connexion with this table. Firstly, there is a tendency for ratings of Kinsey 6 to occur more often in the failed to improve and failed to complete group than in the improved group, and for ratings of Kinsey 3 and 4 to occur less frequently. Secondly, having a rating of Kinsey 6 is not necessarily a bar to a successful outcome of treatment. It can be seen that 9 of the 19 Kinsey 6 patients made a satisfactory response to treatment. However, it is of some interest to point out that a Kinsey rating is assigned on the basis of interest, practice, and fantasy in the three years previous to presentation, as opposed to the entire lifetime of the individual. Of the nine Kinsey 6 patients who made a satisfactory response to treatment, six had displayed heterosexual interest and practice at some stage of their lives previous to the three years immediately before presentation, and of the other three patients none had started actively practising heterosexually. By way of contrast, only 2 of the 10 with a rating of Kinsey 6 who either failed to improve or failed to complete treatment had had heterosexual practice or arousal in the years previous to the three years immediately before presentation. In both instances the patients were very well integrated into the homosexual world.

TABL IX - Pretreatment Kinsey Ratings and Response to Treatment of TABLE IX.- Pretreatment Kinsey Ratings and Respote Groups

\begin{tabular}{|c|c|c|c|c|c|c|}
\hline \multirow{2}{*}{\multicolumn{2}{|c|}{ Response }} & \multicolumn{4}{|c|}{ Kinsey Rating } & \multirow{2}{*}{ Total } \\
\hline & & 3 & 4 & 5 & 6 & \\
\hline \multicolumn{2}{|c|}{ 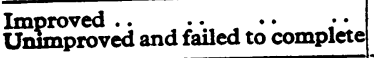 } & $\begin{array}{l}3 \\
2 \\
\end{array}$ & $\begin{array}{l}5 \\
2 \\
\end{array}$ & $\begin{array}{l}8 \\
4 \\
\end{array}$ & $\begin{array}{r}9 \\
10 \\
\end{array}$ & 25 \\
\hline Total & $\cdots$ & 5 & 7 & 12 & 19 & 43 \\
\hline
\end{tabular}

\section{Age and Success}

Table $\mathrm{X}$ shows the age range and outcome of treatment. Of the 23 patients under the age of 30,16 made a successful response to treatment, whereas of the 20 patients over the age 
of 30 , nine did so, indicating a tendency for the younger patients to respond better than the older ones. This was of course expected. What was not expected was that four of the nine patients who were aged over 40 made a successful response to treatment. Two of these patients were married, and therefore had an available heterosexual partner. Of the remaining two, one used strong heterosexual fantasy but had not yet progressed to social mixing. The other patient, who has been followed up for a year and a half, had reached the stage of social mixing with females and was hoping to progress to active heterosexual practice. While, therefore, being over the age of 40 tends to result in a less successful outcome, there are no grounds for complete pessimism.

TABLE X.-Age on Presentation and Response to Treatment

\begin{tabular}{r|c|c|c|c|c|c|c}
\hline Age range: & $15-20$ & $21-25$ & $26-30$ & $31-35$ & $36-40$ & $40+$ & Total \\
\hline $\begin{array}{l}\text { Improved a. . } \\
\text { to complete }\end{array}$ & 3 & 6 & 7 & 4 & 1 & 4 & 25 \\
\end{tabular}

\section{Personality Factors}

Table XI shows the relation between personality disorder and treatment outcome. The presence of personality disorder tends to militate against a successful outcome of treatment. However, Table XII shows that this depends to a considerable degree on the type of personality disorder. Where there is a personality disorder of the self-insecure type, the prospects for a successful outcome are as good as in those who do not display any personality disorder. By way of contrast, where there is a dis-

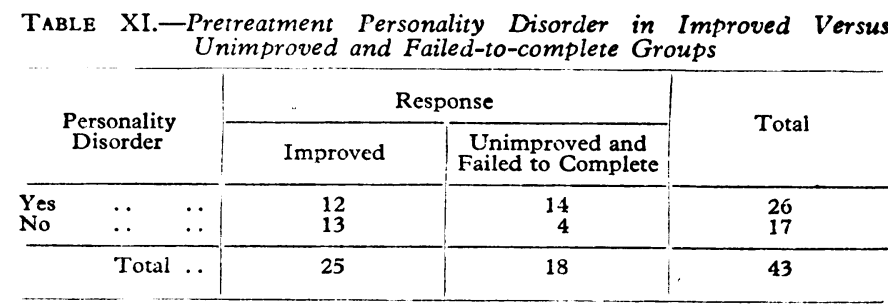

TABLE XII.-Type of Personality Disorder and Response to Treatment

\begin{tabular}{|c|c|c|c|c|}
\hline \multicolumn{3}{|c|}{$\begin{array}{l}\text { Personality } \\
\text { Disorder }\end{array}$} & Improved & $\begin{array}{c}\text { Unimproved Plus Failed } \\
\text { to Complete }\end{array}$ \\
\hline $\begin{array}{l}\text { Nil } \ldots \\
\text { Self-insecure ... } \\
\text { Other disorders }\end{array}$ & $\because$. & $\begin{array}{l}. . \\
.\end{array}$ & $\begin{array}{c}13 \\
11 \\
1\end{array}$ & $\begin{array}{r}4 \\
2 \\
12\end{array}$ \\
\hline & & & 25 & 18 \\
\hline
\end{tabular}

order other than of the self-insecure type-usually of the weakwilled or attention-seeking type-then the prospects for a successful outcome are extremely poor. Three of the four patients who displayed no personality disorder and who made an unsuccessful response to treatment were very well integrated in the homosexual social world and all four were rated as Kinsey 6. One patient who displayed a self-insecure personality disorder failed to complete treatment, having been discharged from the ward by another psychiatrist. One other patient with a self-insecure disorder made a successful response to treatment but is presumed to have relapsed because of failure to keep follow-up appointments.

\section{Conclusions}

The data presented above show that those patients who failed to respond to treatment tended to have a high Kinsey rating, to be over 30, and to have a personality disorder other than of the self-insecure type. There is also considerable evidence that one of the major variables prognostic of success is a history of heterosexual interest and practice at some time in the patient's life, whether or not a Kinsey rating of 6 is appropriate on presentation.

It is of interest to make a brief comparison of our patients with those of other reported series, particularly those of Woodward (1958) and Curran and Parr (1957). Of our 31 patients with an initial Kinsey rating of 5 or 6,17 improved, whereas of Curran and Parr's 23 follow-up patients with an initial Kinsey rating of 5 or 6 , only one showed a change in preference towards heterosexuality. Only seven of Woodward's sample of 48 who completed treatment showed decreased homosexuality and increased heterosexuality immediately at the end of treatment, and all of these were "bisexual" (presumably Kinsey 2, 3, or 4) before treatment. No detailed follow-up data are available for Woodward's series.

It is unlikely that the patient-therapist relationship, which inevitably develops even in the context of behaviour therapy, can entirely account for our success rate. The rate of improvement achieved by experienced psychotherapists in comparable series of homosexual patients has in no instance exceeded $27 \%$ (Bieber et al., 1962). In our opinion the approximately $60 \%$ rate of improvement achieved in our series is mainly due to the use of an aversion therapy technique which has been carefully designed to make the most effective use of the findings of the experimental psychology of learning (Kimble, 1961). However, we are also of the opinion that verbal communication of a supportive and directive kind has been of value. Merely to treat our patients as laboratory subjects might not have been sufficient either to support them during the early period of treatment, before change becomes noticeable, or to assist them through the difficult period immediately after treatment. It is in this latter period, when the patient is learning to employ new or, at best, dormant social skills in the heterosexual area, that relapse seems particularly likely.

Recent work by Argyle and Kendon (1967) on the acquisition of social skills is of great potential value in assisting the transition from homosexual to heterosexual social adaptation. Until this more systematic approach becomes available, verbal support, even of an unsystematic nature, seems valuable. The patients in the present series were followed up at increasing intervals of time, and were on average interviewed on six to eight occasions in the year following completion of treatment.

\section{Summary}

An anticipatory avoidance aversion therapy is described in the treatment of 45 homosexuals. Thirty-six patients completed treatment and 25 of them were significantly improved (14 Kinsey 0, 9 Kinsey 1, and 2 Kinsey 2). This figure (58\%) is unusually high, and it is believed that the appropriateness of the learning technique is mainly responsible for the results, which have remained valid over a one-year follow-up. Some prognostic features are discussed.

We wish to thank the director of the Department of Psychiatry at Crumpsall Hospital, Manchester, Dr. N. J. De V. Mather, for his constant interest and encouragement.

\section{REFERENCES}

Argyle, M., and Kendon, A. (1967). In Advances in Experimental Social Psychology, vol. 3, edited by L. Berkovitz. London. In press. Bieber, I., et al. (1962). Homosexuality. New York. Curran, D., and Parr, D. (1957). Brit. med. F., 1, 797. Feldman, M. P. (1966). Psychol Bull., 65, 65. - and MacCulloch, M. J. (1964). Amer. F. Psychiat., 121, 167. Freund (1965), Behav. Res. Ther., 2, 165. Freund, K. (1960). In Behaviour Therapy and the Neuroses, edited by

Kimble, G. (1961). In E. R. Hilgard and D. G. Marquis's Conditionin and Learning, 2nd ed. London.

Kinsey, A. C., Pomeroy, W. B., and Martin, C. E. (1948). Sexual Behaviour in the Human Male. Philadelphia.

Schneider, K. (1958). Psychopathic Personalities. London. 